\title{
Electrochemical Oxidation of Sulfide Ions on Platinum Electrodes
}

\author{
F. M. Al Kharafi, A. Y. Saad, B. G. Ateya \& I. M. Ghayad (Corresponding author) \\ Chemistry Department, Faculty of Science, Kuwait University, Kuwait \\ P.O. Box: 5969, Safat 13060, Kuwait \\ Central Metallurgical Research and Development Institute (CMRDI) \\ P.O. Box: 87, Helwan, Cairo, Egypt \\ Tel: 96-5-2498-7142 E-mail: ighayad@yahoo.com
}

The research is funded by Research Administration of Kuwait University, Grant Numbers SC04/04.

\begin{abstract}
This paper treats the electrochemical oxidation of sulfide ions on platinum using cyclic voltametry. An electrolyte of $3.5 \% \mathrm{NaCl}$ containing sulfide ions was used as the testing medium. The effects of scan rate, concentration of sulfide ions and temperature on the cyclic voltamograms were investigated.

Cyclic voltamograms show small currents in the absence of sulfide ions. In the presence of sulfide ions, the magnitude of the anodic currents in the forward sweep is much more than these in the reverse sweep. Cyclic voltamograms show three features appear in the forward sweep at potentials of $-0.1,0.475$ and $1.0 \mathrm{~V}$ vs Ag/AgCl, respectively. Peaks currents are increased upon the increase of either the scan rate or temperature. These peaks are explained to show the possible formed species and the possible electrochemical oxidation reactions at the electrode surface.
\end{abstract}

Keywords: Electrochemical oxidation, Platinum, Sulfide ions, Cyclic voltametry

\section{Introduction}

Hydrogen sulfide, $\mathrm{H}_{2} \mathrm{~S}$, is a dangerous pollutant that promotes the corrosion of metallic materials and is toxic to humans. It is listed by the Environmental Protection Agency as an extremely hazardous (U.S. Environmental Protection Agency 1988). It contaminates massive volumes of natural water bodies and industrial waste water streams [Radford et al., 1994; Luther III et al., 1989; Cutter et al., 1989; Xu et al., 2000; Cutter et al., 1999). A prominent example of a sulfide polluted natural water body is the geothermal fluids that encountered during the drilling of wells for the production of oil and gas and for the recovery of geothermal energy (Darely et al., 1988; Garverick 1994; Kagel 2008; Clauser 2006). Various lines of treatment have been proposed for the removal of sulfide ions from contaminated waters, including biological treatment (Park 2008)], adsorption (Daley et al., 1997), oxidation (Anani et al., 1990; Miller et al., 2005). Electrochemical desulfurization (oxidation) of these contaminated waters provides an environmentally friendly alternative, in view of the fact that it utilizes electrons instead of chemicals.

The electrochemical oxidation of sulfide ions has been the subject of much interest in connection with the possible use of $\mathrm{H}_{2} \mathrm{~S}$ as a fuel in fuel cells ( $\mathrm{Li}$, et al. 2006), the current and potential oscillations occurring during electrochemical oxidation (Chen et al., 2004; Miller et al., 2005, Miller, et al. 2006), gas sensors (Mohtadi, et al. 2005), wastewater (Ateya et al., 2007; Ateya et al., 2009) ...etc. Anodic oxidation of sulfide ions can yield a variety of products e.g. elemental sulfur, polysulfide, thiosulfates and sulfates. Determination of the selectivity of anodic reactions and the concentrations of formed species are major tasks that are yet to be achieved.

The objective of this work is to study the electrochemical oxidation of sulfide ions on polycrystalline platinum electrode using cyclic voltametry.

\section{Experimental}

\subsection{Corrosion cell and electrodes}

Measurements were performed using a double jacketed polarization cell $(100 \mathrm{ml})$ with an $\mathrm{Ag} / \mathrm{AgCl}$ reference electrode $(\mathrm{E}=0.197 \mathrm{~V}(\mathrm{SHE}))$ and a platinum wire counter electrode. The working electrodes were polycrystalline platinum sheets of thickness $0.25 \mathrm{~mm}$ (Alfa, 99.99\%) with rectangular shape and an area of $1.5 \mathrm{~cm}^{2}$. The exposed surface of each 
electrode was polished successively down to 0.3 and $0.05 \mu \mathrm{m}$ alumina and cleaned for using acetone in an ultrasonic bath for $10 \mathrm{~min}$. All The potential of the working electrode was scanned from cathodic towards anodic potentials using a Gamry (PC4/750 Potentiostat/Galvanostat/ZRA).

\subsection{Chemicals and reagents}

Measurements were performed in an electrolyte of 3.5\% (0.58 M) NaCl containing different concentrations of sodium sulfide. This supporting electrolyte maintains the ionic strength of the electrolyte nearly constant and hence minimizes double layer effects on the kinetic parameter. The test solutions were prepared from deionized water, $\mathrm{NaCl}(\mathrm{BDH})$ and $\mathrm{Na}_{2} \mathrm{~S}$ (BDH). The concentration of sulfide ions was determined iodimetrically. In view of the values of pK1 and pK2 of $\mathrm{H}_{2} \mathrm{~S}$ (7 and 14, respectively), the predominant species in this electrolyte is $\mathrm{HS}^{-}$at $\mathrm{pH}$ values from 9 to 12 . The temperature of the test electrolyte was controlled by flowing hot water around the cell through its double jacketed walls.

\subsection{Testing methods}

The platinum electrodes were tested using cyclic voltametry method. The potential of the working electrode was scanned from cathodic towards anodic potentials using a Gamry (PC4/750 Potentiostat/Galvanostat/ZRA). Potentioststic experiments were also performed. The electrodes surfaces were examined using an X-ray photoelectron spectrometer, FISONS Instruments, Model ESCA-Lab 200 (VG Instruments).

\section{Results and Discussion:}

Cyclic voltamograms of polycrystalline platinum were measured in $3.5 \% \mathrm{NaCl}$ solution in the absence and in the presence of sulfide ions. Measurements were carried out under different conditions of sulfide ion concentrations, scan rates and temperatures. Results are presented below.

\subsection{Effect of sulfide ion}

Figure (1) illustrates the cyclic voltammogram (CV) of the platinum electrode in the absence and in the presence of sulfide ions. The range of potentials for this $\mathrm{CV}$ was chosen to avoid hydrogen and oxygen evolution. This figure reveals some important features:

1) The anodic currents measured in the absence of sulfide ions are negligibly small compared to those measured in its presence, at all potentials. This indicates that the anodic currents shown in figure (1) are indeed resulting from the oxidation of the sulfide ions.

2) In the presence of sulfide ions, only anodic currents are measured in the forward sweep while the magnitude of currents in the reverse sweep in negligibly small. This indicates that the products of the anodic reaction in the forward sweep do not undergo reduction in the reverse sweep and have passivated the platinum surface.

3) Three features appear in the forward sweep, marked a, b and c at potentials of $-0.1,0.475$ and $1.0 \mathrm{~V}$, respectively. While features $a$ and $c$ readily defined, feature $b$ is less clear.

As can be noticed from figure (2) which represents a consecutive CV's of platinum electrode in a solution of $3.5 \% \mathrm{NaCl}$ containing $0.15 \mathrm{M} \mathrm{HS}^{-}$at scan rate $10 \mathrm{mV} \mathrm{s}^{-1}$ and $25^{\circ} \mathrm{C}$, the value of the current of the first peak is not changed indicating that the formed layer at this potential is not affected markedly by the number of cycles. While the second peak markedly decreased, which may be due to the consuming of active species nearby the surface of the working electrode stepwise and at the mean time, the platinum surface was passivated at the first cycle and its electrochemical ability was decreased due to more sulfur formed at this potential (b). This is also the reason for the disappearance of the peak (c), which is related also to the formation of sulfur species.

Figure (3) illustrates the effect of sulfide ion concentration on the cyclic voltamogram of platinum electrode in $3.5 \%$ $\mathrm{NaCl}$ at room temperature. The formations of three peaks were gradually disappeared by decreasing the $\mathrm{HS}^{-}$ concentration and the appearance of the will defined reduction peak in the reverse direction was noticed. In this case the passivity of platinum electrode was decreased by the gradual decrease of $\mathrm{HS}^{-}$ion concentration.

\subsection{Effect of scan rate}

Figure (4) illustrates the effect of the scan rate on the cyclic voltammograms of polycrystalline platinum in $3.5 \% \mathrm{NaCl}$ solution containing $0.15 \mathrm{M} \mathrm{HS}^{-}$. It can be noted that there are increases of the values of all peaks current $\left(\mathrm{I}_{\mathrm{p}}\right)$ with the increase of scan rate $(v)$. The scan rate dependence of all peaks current, $I_{p}$, and peaks potential, $E_{p}$, are shown in Figures (5-6), respectively. There is a linear relationship in the plots between $I_{p}$ versus $v^{1 / 2}$ and $I_{p}$ versus $\log v$ which indicates that the oxidation reaction involves an irreversible electron transfer and is under diffusion control (Ateya et al., 2007).

\subsection{Effect of temperature}

Figure (7) shows the effect of temperature on the cyclic voltammograms of poly crystalline platinum in $3.5 \% \mathrm{NaCl}$ solution containing $0.15 \mathrm{M} \mathrm{HS}^{-}$at a scan rate $10 \mathrm{mVs}^{-1}$. As can be seen, all peaks currents are increased due to the 
increasing of the rate of the oxidation reaction. Furthermore, the three peaks are formed at less positive potential values i.e. more readily to be occurred.

Arrhenius plots of the results shown in figure (7) are displayed in figure (8). The Arrhenius equation for many electrode reactions in aqueous solutions is given below (Laidler 1993):

$i=\mathrm{A} \exp \left(-\Delta \mathrm{H}^{\ddagger} / \mathrm{RT}\right)$

where $\Delta \mathrm{H}^{\neq}$is the enthalpy of activation and $\mathrm{A}$ is the pre-exponential factor, which includes the entropy of activation, $\Delta \mathrm{S}^{\ddagger}$, since the free energy of activation is related to $\Delta \mathrm{S}^{\ddagger}$ by this equation: $\Delta \mathrm{G}^{\ddagger}=\Delta \mathrm{H}^{\ddagger}-\mathrm{T} \Delta \mathrm{S}^{\ddagger}$, then equation 2 becomes:

$i=\mathrm{A} \exp \left(-\Delta \mathrm{G}^{\ddagger} / \mathrm{RT}\right)$

From the slope of straight lines in figure $8, \Delta \mathrm{G}^{\neq}$can be measured for each peak. $\Delta \mathrm{G}^{\ddagger}$ values of $12.7,9.23$ and $11.37 \mathrm{KJ}$ $\mathrm{mol}^{-1}$ are obtained for the first, second and third peaks respectively. The low values of $\Delta \mathrm{G}^{\neq}$indicate the ease of occurrence of electroxidation reactions at these potentials. The lowest activation energy is given by the second peak which is shown below to be the starting potential of sulfur deposition.

\subsection{Proposed Mechanism of sulfur electrodeposition}

The following anodic reactions are expected to occur in the sulfide system, resulting in the formation and removal of sulfur layer (Feng et al., 2005; Kapusta et al., 1987; Mohtadi et al., 2005; Ramsubramanian 1975):

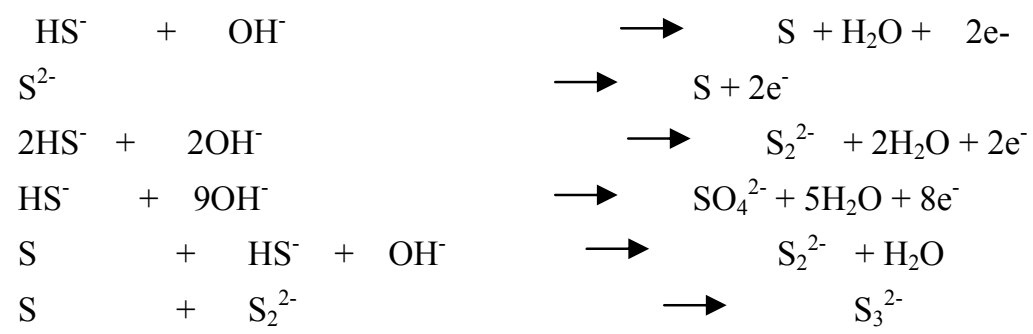

In view of the values of $\mathrm{pK}_{1}$ and $\mathrm{pK}_{2}$ of $\mathrm{H}_{2} \mathrm{~S}$ (7 and 14, respectively), the predominant species in this electrolyte is $\mathrm{HS}^{-}$ at $\mathrm{pH}$ values from 9 to 12 . By sweeping the electrode potential towards more positive (figure 1), a small shoulder at point (b) is formed which may be due to the starting point of the deposition of elemental sulfur. The starting of formation of white thin layer adherent to the electrode surface was observed exactly at this potential. Such formation causes the reduction in the size of effective surface of the Pt electrode. The formation of large peak afterward at point (c) (see figure 1) can be explained on the basis of the oxidation of the deposited sulfur according to the equation (12) to form soluble sulfate ions. The phenomenon of periodic formation and dissolution of sulfur element on the Pt electrode could be represented as follows:

$$
\begin{aligned}
& \mathrm{Pt}+\mathrm{HS}^{-}+\mathrm{OH}^{-} \longrightarrow \mathrm{PtS}+\mathrm{H}_{2} \mathrm{O}+2 \mathrm{e}^{-} \\
& \mathrm{PtS}+\mathrm{HS}_{\mathrm{x}}^{-} \rightarrow \mathrm{Pt}+\mathrm{HS}_{\mathrm{x}+1}{ }^{-} \\
& \mathrm{PtS}+8 \mathrm{OH}^{-} \rightarrow \mathrm{Pt}+4 \mathrm{H}_{2} \mathrm{O}+\mathrm{SO}_{4}{ }^{2-}+6 \mathrm{e}^{-}
\end{aligned}
$$

The above mechanism is substantiated by XPS performed on the electrodes surface after potentiostatic experiments. Many XPS spectra of polycrystalline platinum polarized at different potentials in sulfide polluted salt water were measured. An illustrative example of these spectra is shown in figure (9). It shows XPS spectrum of platinum electrode polarized at a potential of $1.0 \mathrm{~V}$ for 60 minutes containing $0.15 \mathrm{M} \mathrm{HS}^{-}$. A sharp S2p peak appears at $163.2 \mathrm{eV}$ (referred to $\mathrm{C} 1 \mathrm{~s}$ at $284.6 \mathrm{eV}$ ), which is characteristic of the presence of elemental sulfur (S) on the electrode (Wagner 1990). As can be seen in figure (9), a small shoulder appears at $169.2 \mathrm{eV}$ which indicates the presence of sulfate $\left(\mathrm{SO}_{4}{ }^{2-}\right)$ ions. This is due to the partial oxidation of deposited sulfur at $1.0 \mathrm{~V}$.

\section{Summary and Conclusions}

Cyclic voltamograms of polycrystalline platinum show negligibly small currents in the absence of sulfide ions compared to those measured in its presence, at all potentials. These anodic currents are indeed resulting from the oxidation of the sulfide ions. The magnitude of currents measured in the reverse sweep is much less than those measured in the forward sweep which reveals that the reaction products in the forward sweep have passivated the platinum surface. Three current peaks appear in the forward sweep at potentials of $-0.1,0.475$ and $1.0 \mathrm{~V}$, respectively. The first peak indicates the possibility of the formation of platinum sulfide and poly sulfide. The second peak may be due to the starting point of the deposition of elemental sulfur. A white thin layer adherent to the electrode surface starts exactly at this potential. The third peak can be explained on the basis of the oxidation of the deposited sulfur to form soluble sulfate ions. 


\section{References}

Anani, A., Mao, Z., White, R. E., Srinivasan, S. \& Appleby, A. J. (1990). Electrochemical production of hydrogen and sulfur by low-temperature decomposition of hydrogen sulfide in an aqueous alkaline solution. J. Electrochem. Soc., $137-2703$.

Ateya, B. G., Alkharafi, F. M., Alazab, A. S. \& Abdullah, A. M. (2007). Kinetics of the electrochemical deposition of sulfur from sulfide polluted brines. J. App. Electrochem., 37, 395-404.

Ateya, B. G., Alkharafi, F. M., El-Shamy, A.M., Saad, A. Y. \& abdalla, R. M. (2009). Electrochemical desulfurization of geothermal fluids under high temperature and pressure. J. App. Electrochem., 39, 383-389.

Chen, A. \& Miller., B. (2004). Potential oscillations during the electrocatalytic oxidation of sulfide on a microstructured $\mathrm{Ti} / \mathrm{Ta}_{2} \mathrm{O}_{5}-\mathrm{IrO}_{2}$ electrode. J. Phys. Chem. B, 108, 2245-2251.

Clauser, C. (2006). Geothermal Energy, In: K. Heinloth (ed), Landolt-Börnstein, Group VIII: Advanced Materials and Technologies, Vol. 3: Energy Technologies, Subvol. C: Renewable Energies (493-604), Springer Verlag, Heidelberg-Berlin.

Cutter, G. A. and Krahforst, C. F. (1989). Sulfide in surface waters of the western Atlantic Ocean. Geophys. Res. Lett., 15, (12) 1393-1396.

Cutter, G. A., Walsh, R. S. \& de Echols, C. S. (1999). Topical Studies in Oceanography. Deep-Sea Res II, 46, 991-1010.

Darely, H. C. H. \& Gray, G. R. (1988). Composition and Properties of Drilling and Completion Fluids, $5^{\text {th }}$ ed., Gulf Publishing Company, Houston (p.477).

Daley, M. A., Mangun, C. L., DeBarr, J. A., Riha, S., Lizzio, A. A., Donnals, G. L. \& Economy, J. (1997). Adsorption of $\mathrm{SO}_{2}$ onto oxidized and heat-treated activated carbon fibers (ACFs). Carbon, 35, 411-417.

Feng, J., Gao, Q., Xu, L. \& Jichang Wang. J. (2005). Nonlinear phenomena in the electrochemical oxidation of sulfide. Electrochemistry Communications, 7, 1471-1476.

Garverick, L. (1994). Corrosion in the Petrochemical Industry, ASM International, Metals Park, Ohio (p. 259).

Kagel, A. (2008). The State of Geothermal Technology, Part II: Surface Technology, The Department of Energy, Washington, D. C. (p 5).

Kapusta, S., Viehbeck, A., Willhel, S. M. \& Hackerman, N. (1987). The anodic oxidation of sulfide on platinum electrodes. J. Electroanal. Chem., 153, 157-174.

Laidler, K. J. (1993). The World of Physical Chemistry, Oxford University Press, Oxford. Li Zhong, Ming QI, Guolin WEI, Jingli LUO and, Chuang, K. (2006). An Intermediate-temperature $\mathrm{H}_{2} \mathrm{~S}$ Fuel Cell with a $\mathrm{Li}_{2} \mathrm{SO}_{4}$-based Proton-conducting Membrane. Chinese Journal of Chemical Engineering, 14 51-55.

Luther III, G. W. \& Tsamakis, E. (1989). Concentration and form of dissolved sulfide in the toxic water column of the ocean. Mar. Chem,. 27, 165-177.

Mao, Z., Anani, A., White, R. E., Srinivasan, S. \& Appleby, A. J. (1991). A Modified Electrochemical Process for the Decomposition of Hydrogen Sulfide in an Aqueous Alkaline Solution. J. Electrochem. Soc., 138, 1299.

Miller, B. \& Chen, A. (2005). Effect of concentration and temperature on electrochemical oscillations during sulfide oxidation on $\mathrm{Ti} / \mathrm{Ta}_{2} \mathrm{O}_{5}-\mathrm{IrO}_{2}$ electrodes. Electrochimica Acta, 50, 2203-2212.

Miller B., \& Chen, A. (2006). Oscillatory instabilities during the electrochemical oxidation of sulfide on a Pt electrode. J. Electroanal. Chem., 588, 314-323.

Mohtadi, R., Lee, W. K., Van Zee, J. W. (2005). The Effect of Temperature on the Adsorption Rate of Hydrogen Sulfide on Pt Anodes in a PEMFC. Applied Catalysis B: Environmental 56, 37-42.

Mikhalovsky, S. V. \& Zaitsev, Y. P. (1997). Catalytic properties of activated carbons I. Gas-phase oxidation of hydrogen sulphide. Carbon, 35, 1367-1374.

Park, Y. G. (2008). Removal Study of Hydrogen Sulfide Using Natural Second Metabolites. Biotechnology and Bioprocess Engineering, 13, 325-331.

Radford, J. \& Cutter, G. A. (1994). Biogeochemistxy of dissolved hydrogen sulfide species and carbonyl sulfide in the western North Atlantic. Geochim. Cosmochim. Acta, 58, 5421-5431.

Ramsubramanian, N. (1975). Anodic behavior of platinum electrodes in sulfide solutions and the formation of platinum sulfide. J. Electroanal. Chem., 64, 21-37. 
U.S. Environmental Protection Agency (1988). Extremely Hazardous Substances, vol. 1 A-L, Noyes Data Corporation, Park Ridge, New Jersey, USA.

Wagner, C. D. (1990). Auger and X-Ray Photoelectron Spectroscopy. In D. Briggs and M. P. Seath, Practical Surface Analysis (p.595), Vol. 1, 2nd ed., John Wiley \& Sons, New York.

Xu, Y., Shonnen, M. A. A., Nordstram, D. K., Cunningham, K. M. \& Ball, J. W. (2000). Sulfur geochemistry of hydrothermal waters in Yellowstone National Park, Wyoming, USA. II. Formation and decomposition of thiosulfate and polythionate in Cinder Pool, J. Volcanology and Geothermal Research, 97, 407-423.

\section{Figures Captions}

Figure 1. Cyclic voltammograms $\left(1^{\text {st }}\right.$ cycle) of $3.5 \% \mathrm{NaCl}$ solution without (solid line) and with (dashed line) $0.15 \mathrm{M}$ $\mathrm{HS}^{-}$on polycrystalline platinum at scan rate $10 \mathrm{mV} \mathrm{s}^{-1}$ at $25^{\circ} \mathrm{C}$.

Figure 2. Consecutive cyclic voltammograms of $3.5 \% \mathrm{NaCl}$ solution containing $0.15 \mathrm{M}$ HŠon polycrystalline platinum at scan rate $10 \mathrm{mVs}^{-1}$ at $25^{\circ} \mathrm{C}$.

Figure 3. Effect of scan rate on the cyclic voltammograms of $3.5 \% \mathrm{NaCl}$ solution containing $0.15 \mathrm{M} \mathrm{HS}^{-}$on polycrystalline platinum at $25^{\circ} \mathrm{C}$.

Figure 4. Relation between scan rate (v) of the cyclic voltammogrms and the peak currents of $3.5 \% \mathrm{NaCl}$ solution containing $0.15 \mathrm{M} \mathrm{HS}^{-}$on polycrystalline platinum at $25^{\circ} \mathrm{C}$.

Figure 5. Relation between scan rate (v) of the cyclic voltammogrms and the peak potentials of $3.5 \% \mathrm{NaCl}$ solution containing $0.15 \mathrm{M} \mathrm{HS}^{-}$on polycrystalline platinum at $25^{\circ} \mathrm{C}$.

Figure 6. Effect of $\mathrm{HS}^{-}$ions concentration on the cyclic voltammograms $\left(1^{\text {st }}\right.$ cycles) of $3.5 \% \mathrm{NaCl}$ solution on polycrystalline platinum at scan rate $10 \mathrm{mVs}^{-1}$.

Figure 7. Effect of temperature on the cyclic voltammograms ( $1^{\text {st }}$ cycles) of $3.5 \% \mathrm{NaCl}$ solution containing $0.15 \mathrm{M} \mathrm{HS}$ on polycrystalline platinum at scan rate $10 \mathrm{mVs}^{-1}$.

Figure 8. Arrhenius plot of the different peaks of the cyclic voltammograms in Figure (7).

Figure 9. XPS spectrum of a polycrystalline platinum electrode after potentiostatic polarization at $1.00 \mathrm{~V}(\mathrm{Ag} / \mathrm{AgCl})$ for 1 hour in presence of $3.5 \% \mathrm{NaCl}$ solution containing $0.15 \mathrm{M} \mathrm{HS}^{-}$at $25^{\circ} \mathrm{C}$.

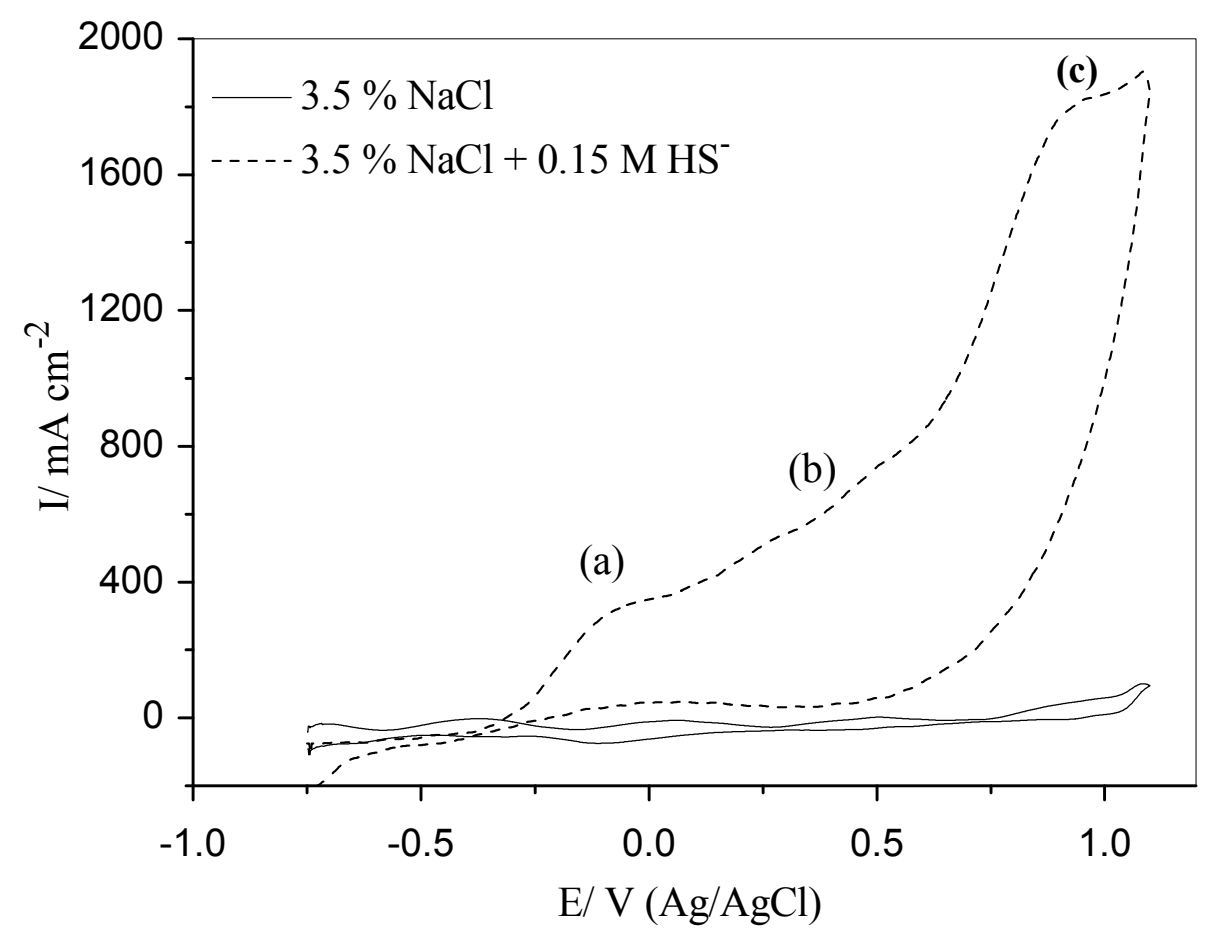

Figure 1. Cyclic voltammograms ( $1^{\text {st }}$ cycle) of $3.5 \% \mathrm{NaCl}$ solution without (solid line) and with (dashed line) $0.15 \mathrm{M}$ $\mathrm{HS}^{-}$on polycrystalline platinum at scan rate $10 \mathrm{mV} \mathrm{s}^{-1}$ at $25^{\circ} \mathrm{C}$. 


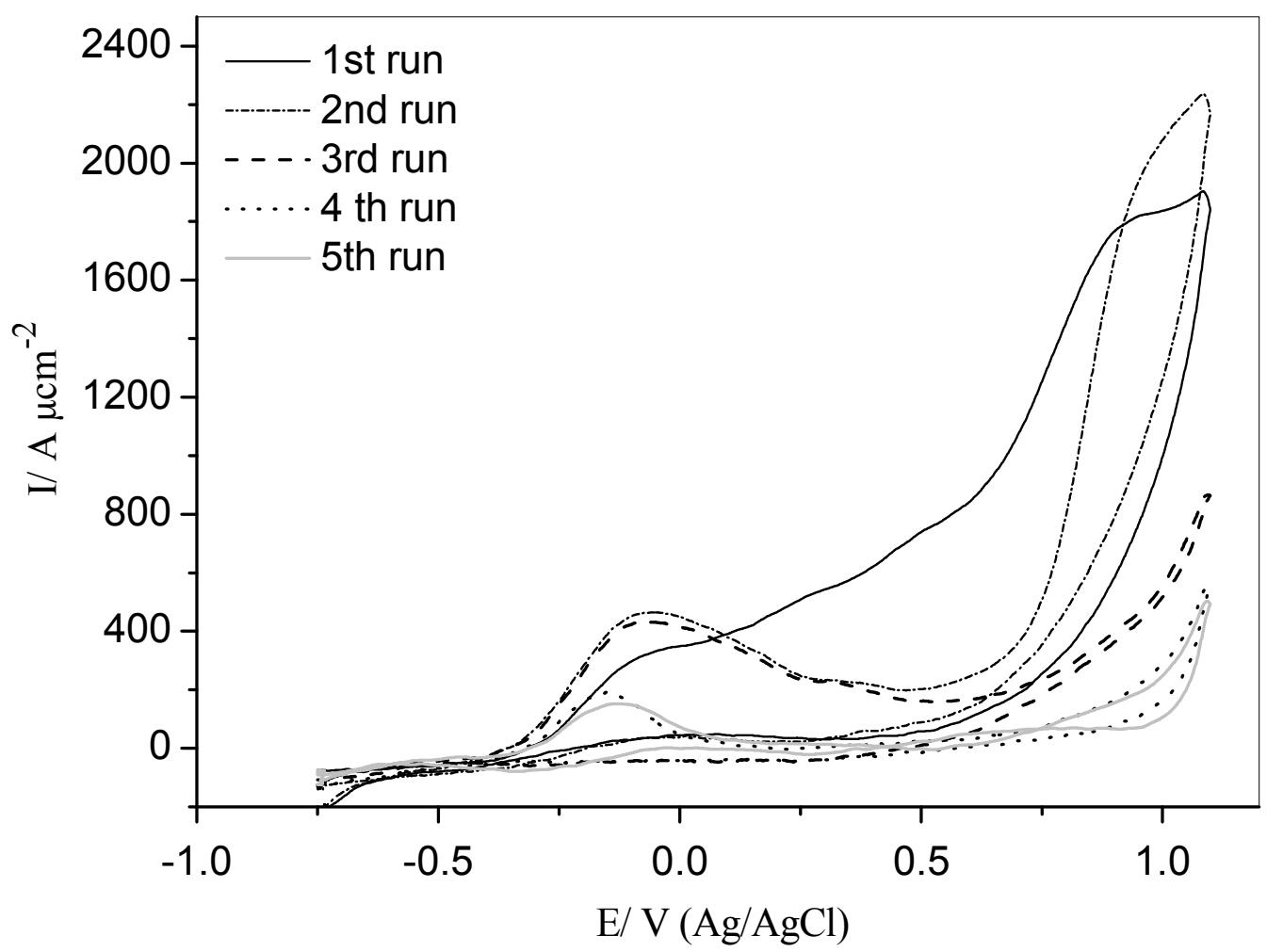

Figure 2. Consecutive cyclic voltammograms of $3.5 \% \mathrm{NaCl}$ solution containing $0.15 \mathrm{M} \mathrm{HS}^{-}$on polycrystalline platinum at scan rate $10 \mathrm{mVs}^{-1}$ at $25^{\circ} \mathrm{C}$.

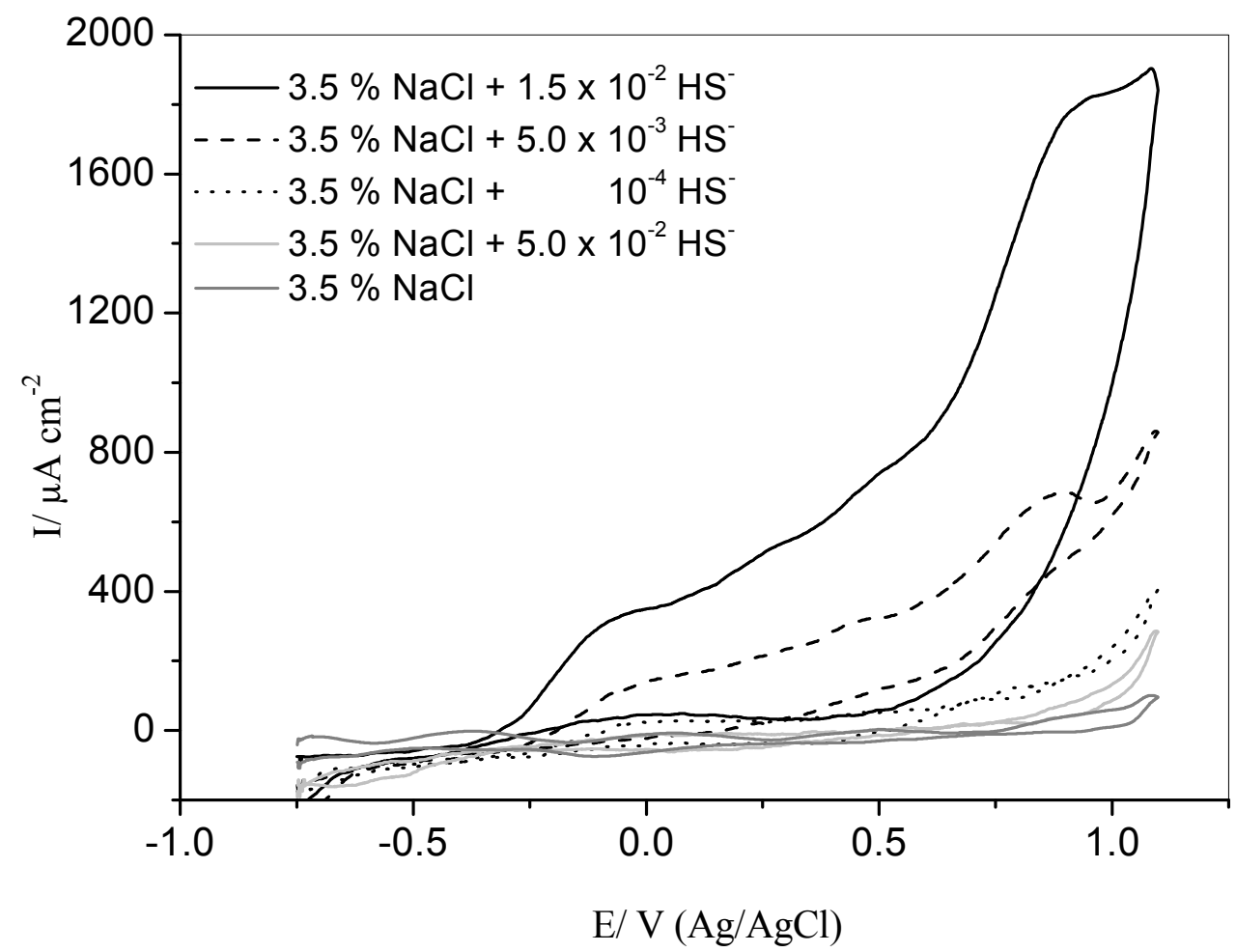

Figure 3. Effect of $\mathrm{HS}^{-}$ions concentration on the cyclic voltammograms $\left(1^{\text {st }}\right.$ cycles $)$ of $3.5 \% \mathrm{NaCl}$ solution on polycrystalline platinum at scan rate $10 \mathrm{mVs}^{-1}$. 


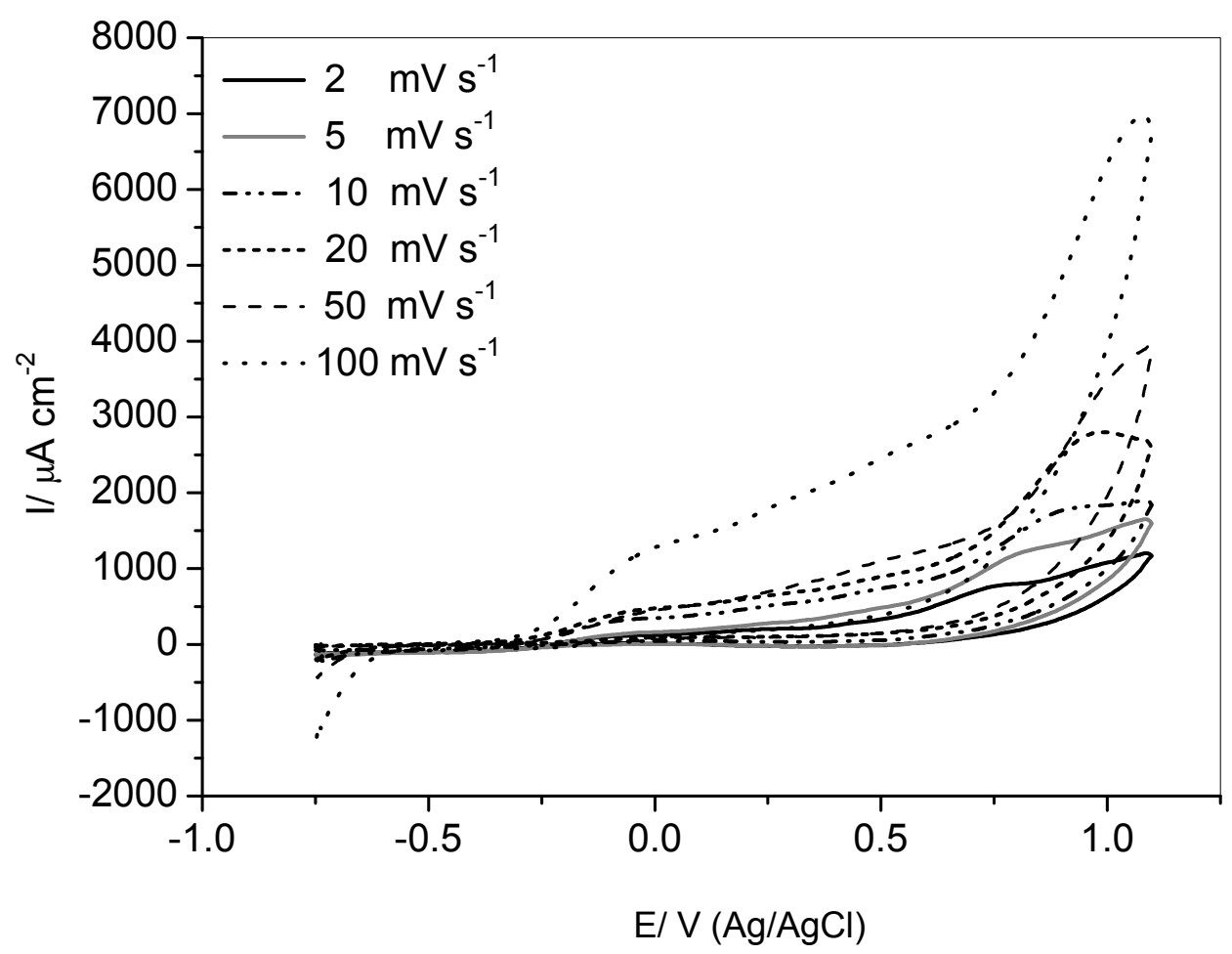

Figure 4. Effect of scan rate on the cyclic voltammograms of $3.5 \% \mathrm{NaCl}$ solution containing $0.15 \mathrm{M} \mathrm{HS}^{-}$on polycrystalline platinum at $25^{\circ} \mathrm{C}$.

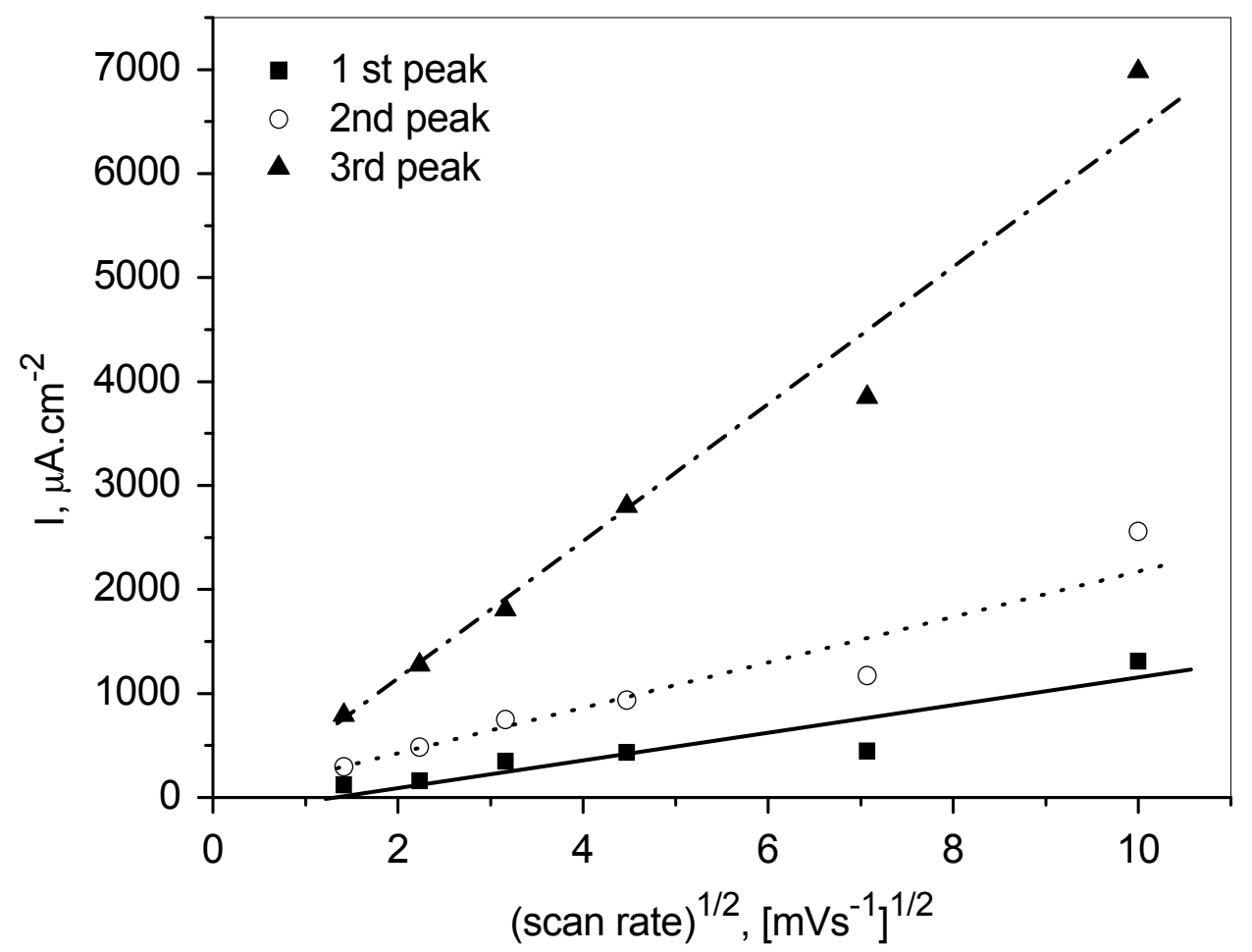

Figure 5. Relation between scan rate (v) of the cyclic voltammogrms and the peak currents of $3.5 \% \mathrm{NaCl}$ solution containing $0.15 \mathrm{M} \mathrm{HS}^{-}$on polycrystalline platinum at $25^{\circ} \mathrm{C}$. 


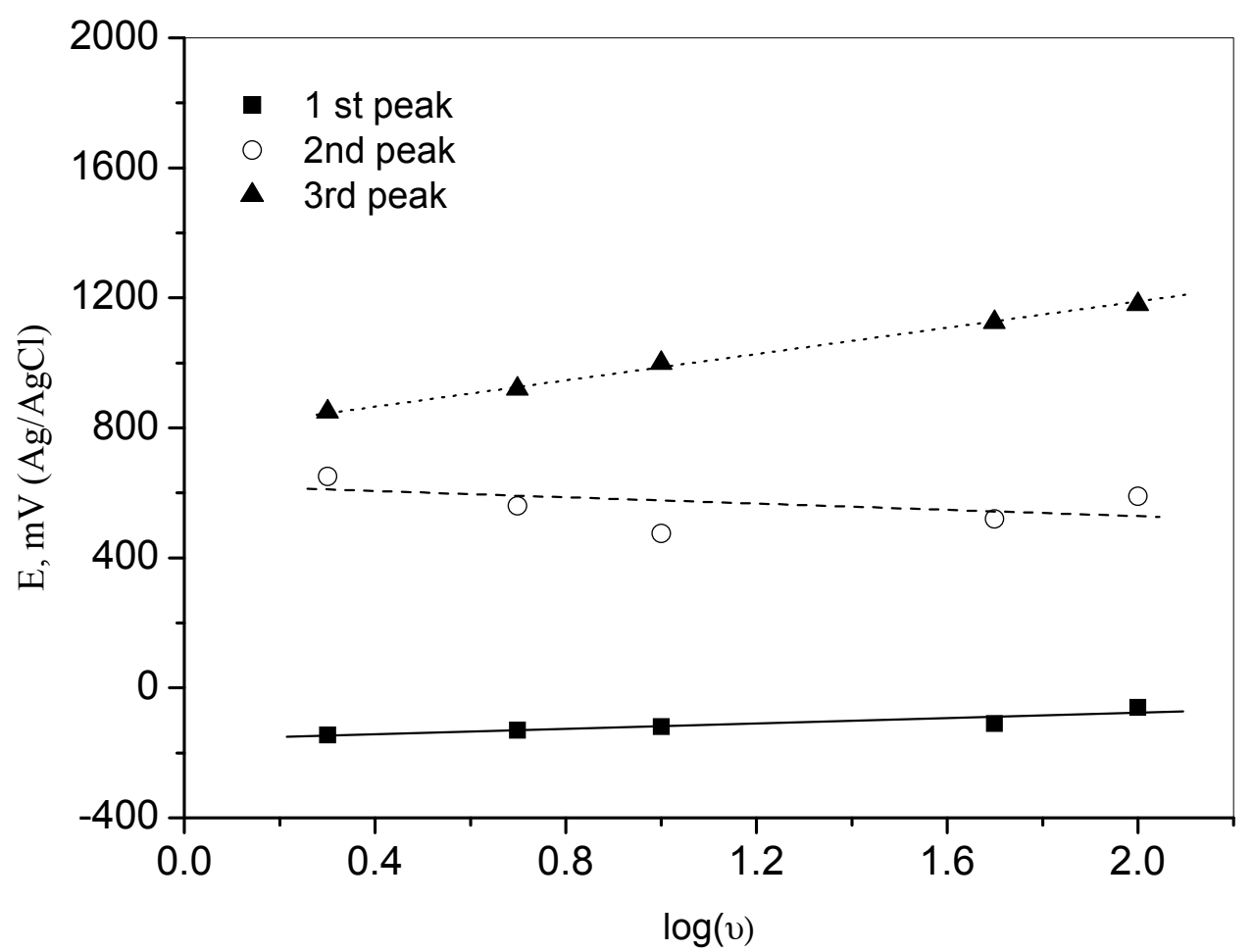

Figure 6. Relation between scan rate (v) of the cyclic voltammogrms and the peak potentials of $3.5 \% \mathrm{NaCl}$ solution containing $0.15 \mathrm{M} \mathrm{HS}^{-}$on polycrystalline platinum at $25^{\circ} \mathrm{C}$. 


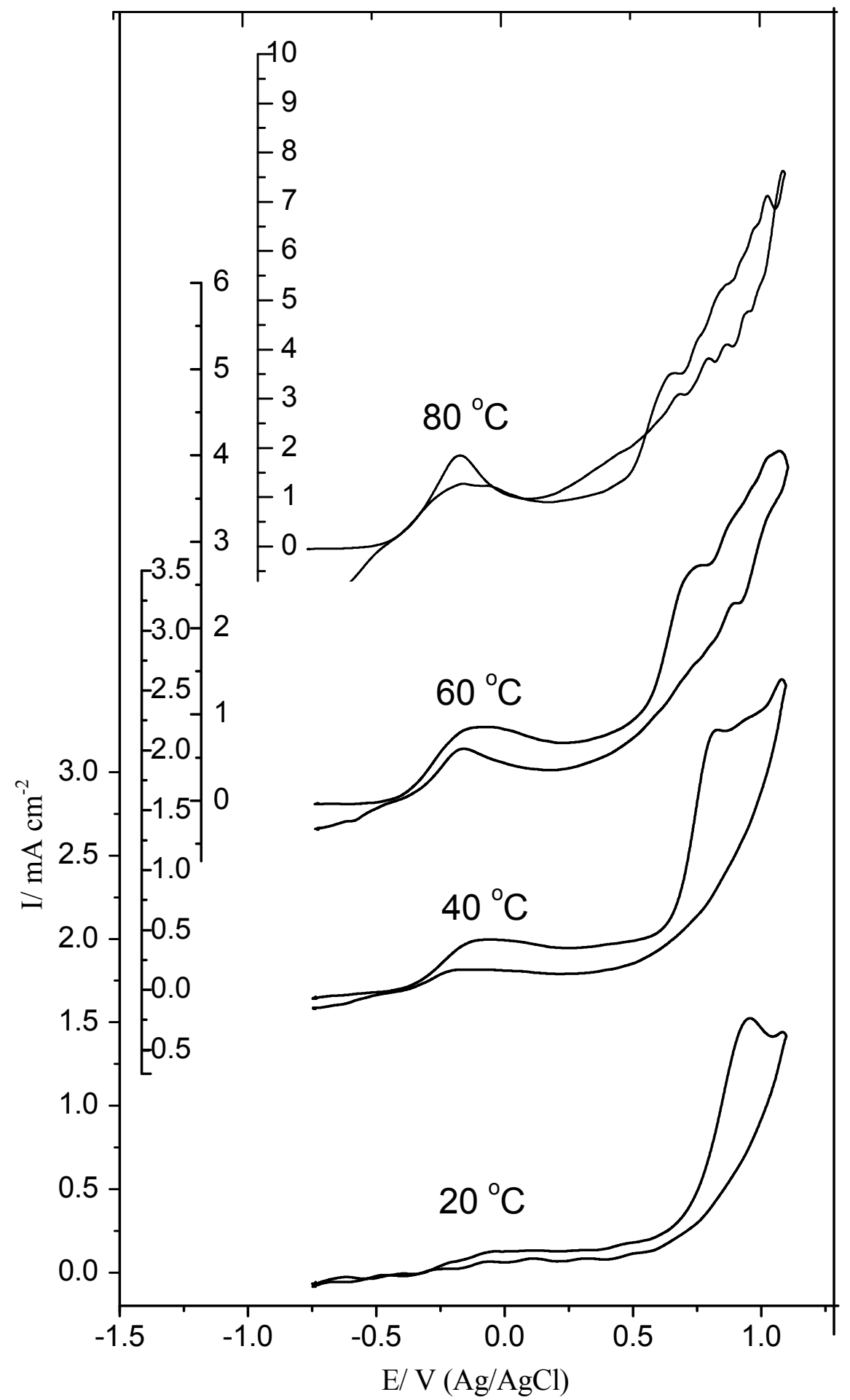

Figure 7. Effect of temperature on the cyclic voltammograms $\left(1^{\text {st }}\right.$ cycles $)$ of $3.5 \% \mathrm{NaCl}$ solution containing $0.15 \mathrm{M} \mathrm{HS}^{-}$on polycrystalline platinum at scan rate $10 \mathrm{mVs}^{-1}$. 


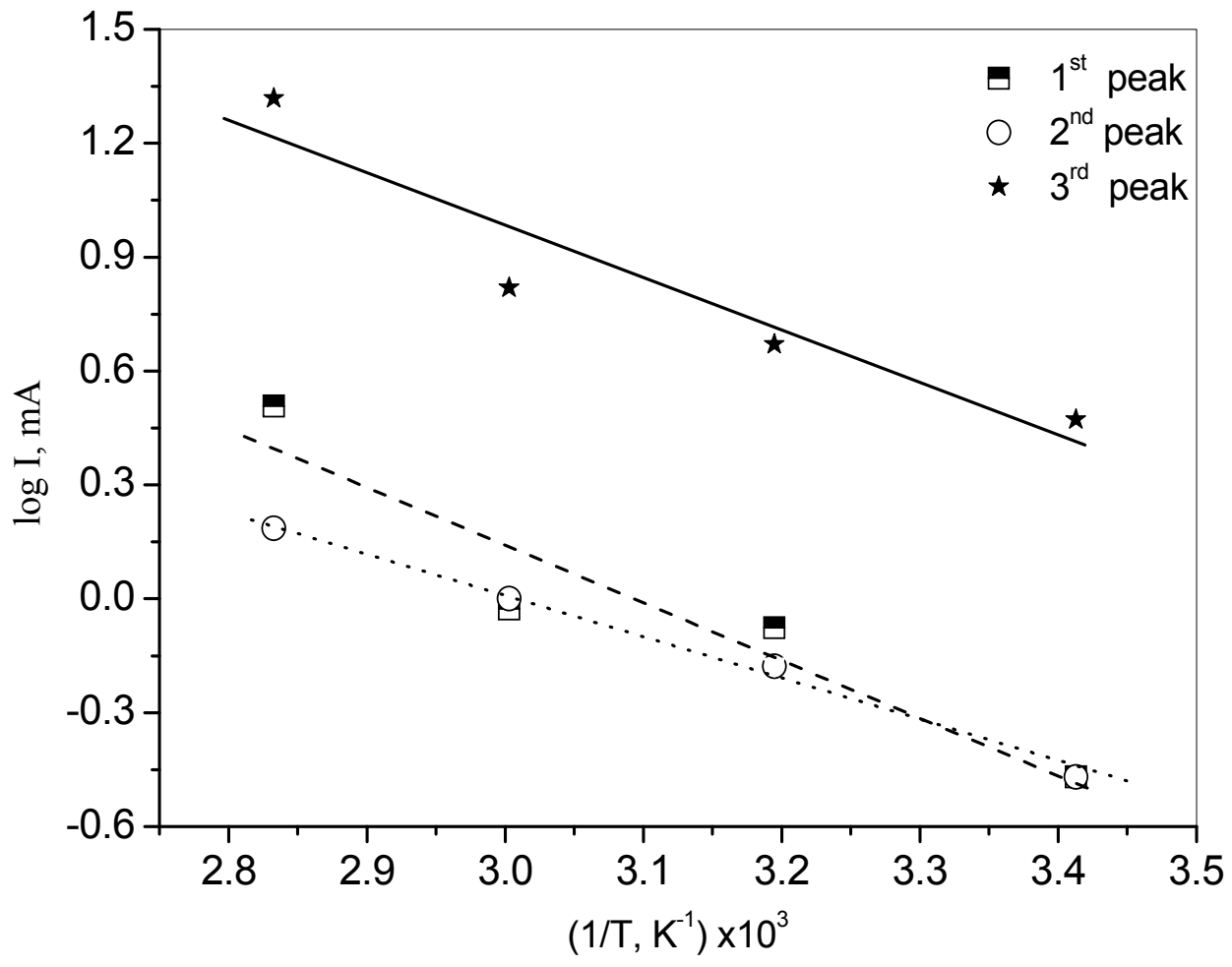

Figure 8. Arrhenius plot of the different peaks of the cyclic voltammograms in Figure (7).

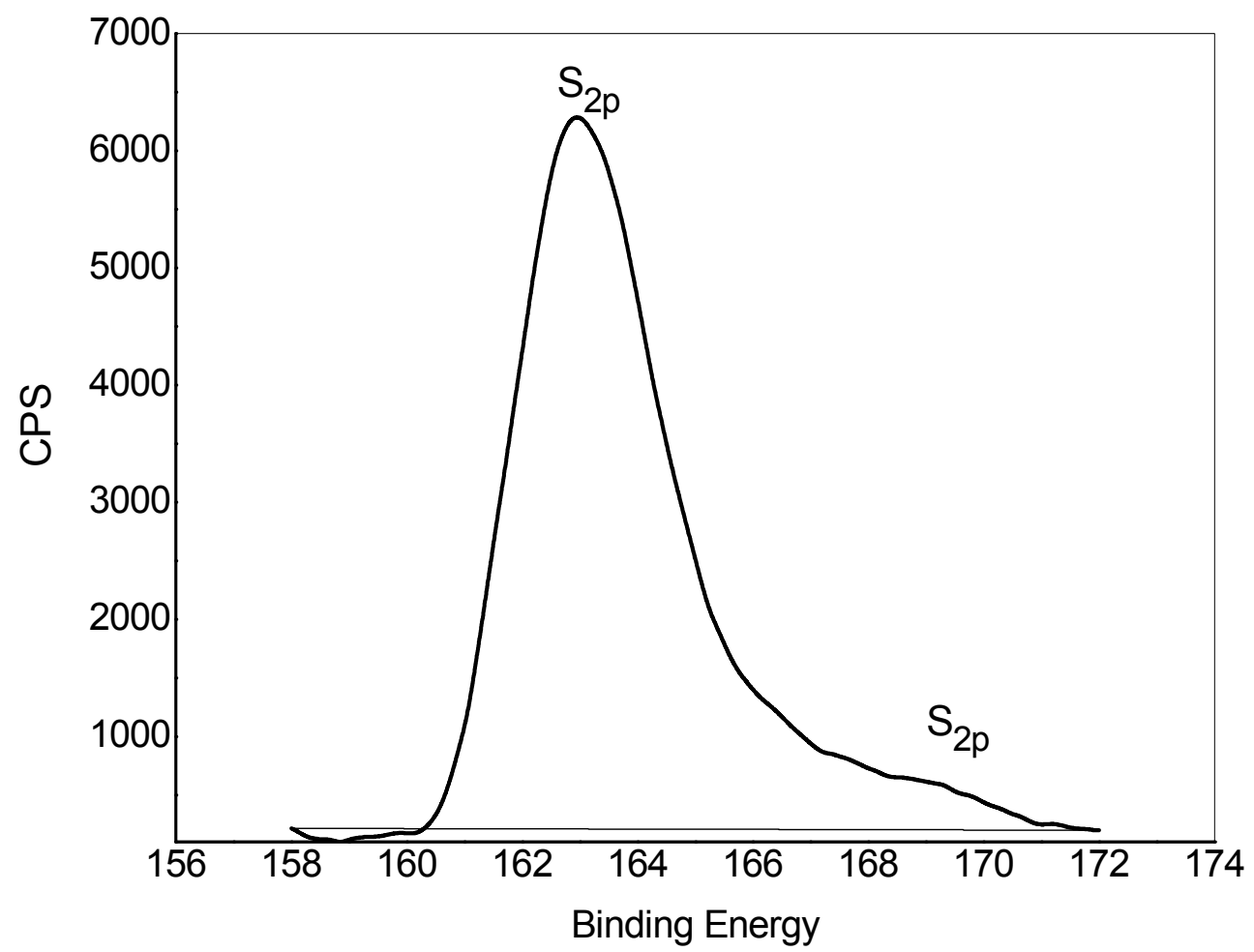

Figure 9. XPS spectrum of a polycrystalline platinum electrode after potentiostatic polarization at $1.00 \mathrm{~V}(\mathrm{Ag} / \mathrm{AgCl})$ for 1 hour in presence of $3.5 \% \mathrm{NaCl}$ solution containing $0.15 \mathrm{M} \mathrm{HS}^{-}$at $25^{\circ} \mathrm{C}$ 